\title{
Relações entre preconceito, ideologia e atitudes frente à educação inclusiva' ${ }^{1}$
}

\author{
Relationships between prejudice, ideology and \\ attitudes towards inclusive education
}

\author{
José Leon CROCHÍK² \\ Ricardo CASCO$^{2}$ \\ Mariane CERON ${ }^{2}$ \\ Fabiana Olivieri CATANZARO2
}

\begin{abstract}
Resumo
Este artigo analisa atitudes de alunos de um curso de pedagogia frente à educação inclusiva. Parte da hipótese de que o preconceito e a ideologia podem ser obstáculos à inclusão de crianças com deficiência na escola. Foram aplicadas quatro escalas: Manifestação de Preconceito, Atitudes Frente à Educação Inclusiva e Ideologia da Racionalidade Tecnológica, elaboradas por Crochík em 2000, 2003 e 2006, e a escala F, construída por Adorno, Frenkel-Brunswik, Levinson e Sanford em 1950. O estudo foi realizado com 188 estudantes de pedagogia. Os alunos desta amostra tenderam a ser mais favoráveis do que desfavoráveis à educação inclusiva, e foi possível verificar que o preconceito, a adesão à ideologia da racionalidade tecnológica e, implicitamente, ao fascismo, são variáveis que se relacionam às atitudes acerca desse tipo de educação.
\end{abstract}

Unitermos: Educação inclusiva. Ideologia. Preconceito. Teoria crítica da sociedade.

\begin{abstract}
This article studies the attitudes of pedagogy students towards inclusive/integrated education. It begins with the hypothesis that prejudice and ideology can be obstacles to the inclusion of children with intellectual disabilities at school. Four ranking scales were applied to 188 pedagogy students: manifestation of prejudice, attitudes towards inclusive/integrated education and the ideology of technological rationality, as created by Crochík (2000, 2003 and 2006), plus the F scale, created by Adorno et al. (1950). The students in this sample tended to be in favor of Inclusive/Integrated Education and we were able to ascertain that prejudice, subscribing to an ideology of technological rationality and inherent fascism are variables related to attitudes on inclusive/integrated Education.
\end{abstract}

Uniterms: Inclusive education. Ideology. Prejudice. Society critical theory.

\section{UTV}

1 Este artigo foi produto de pesquisa realizada com bolsa de Produtividade em Pesquisa do Conselho Nacional de Desenvolvimento Científico e Tecnológico (processo no. 307711/2004-8.

2 Universidade de São Paulo, Instituto de Psicologia. Av. Prof. Mello Moraes, 1721, Sala 164, Cidade Universitária, 05508-900, São Paulo, SP, Brasil. Correspondência para/Correspondence to: J.L. CROCHÍK.E-mail:<jlchna@usp.br>. 
As discussões sobre a implantação e implementação da educação inclusiva no Brasil são recentes, se comparadas às realizadas em países como a Itália e os Estados Unidos. A Itália é considerada o primeiro país a legislar e introduzir um novo sistema educacional radical (implantado em 1971 e implementado em 1975), que compreendeu a eliminação das escolas segregadas e a transferência de todos os alunos com deficiências para as escolas regulares (Mittler, 2003). Os Estados Unidos apresentaram, no final de 1980, uma incorporação de alunos com deficiências em salas comuns de 69,2\% (S. Stainback \&W. Stainback, 1999). Já no Brasil, o movimento da educação inclusiva se institucionalizou em políticas educacionais em meados da década de 1990, com a Lei de Diretrizes e Bases para a educação (Brasil, 1996). Em 2005, o número de alunos com deficiência incorporados à escola, no país, chegou a 41\%, segundo o censo escolar (MEC/INEP, 2005), o que equivale a 262243 alunos com deficiências matriculados em escolas regulares.

Apesar de as políticas de inclusão serem cada vez mais consideradas e adotadas, as concepções que subsidiam as propostas de implantação e implementação da educação inclusiva nos diferentes países, e dentro de um mesmo país, nem sempre são similares.

Um ponto a ser destacado diz respeito às distinções que os autores fazem entre a educação inclusiva e a educação integrada. Ainscow (1997), Mantoan (2003) e Mittler (2003) parecem concordar quando afirmam que, na educação integrada, as crianças com deficiências são colocadas junto às crianças sem deficiências nas salas de aula, sem que necessariamente a escola crie condições favoráveis para recebê-las. Já na inclusiva, a educação estaria voltada para todas as crianças; nesta concepção não é a criança que deve se modificar para a adaptação à vida escolar, mas é a escola que deve ser alterada para o acolhimento das diferenças. Neste artigo, não se faz a distinção entre educação integrada e educação inclusiva (o termo "inclusiva"é usado para se referir aos dois tipos), mas mantém-se a oposição à educação segregada, pois no Brasil a oferta desta última ainda é grande.

Há obstáculos de diversas ordens à implantação da educação inclusiva: os culturais, os ideológicos, os financeiros, os educacionais, os institucionais e as possíveis resistências dos pais das crianças sem defi- ciência, mas as atitudes, principalmente dos professores e dos colegas sem deficiências, frente à inclusão das crianças com deficiência na escola parecem também ser variáveis importantes. Como a educação inclusiva se refere a diversos alvos de preconceito (alunos com deficiência, crianças e jovens que vivem nas ruas, ciganos, índios e, em alguns países, negros e mulheres), esta foi uma variável que precisa ser estudada.

Duckitt (1992) entende o preconceito como uma atitude comum para certo número de pessoas, que percebem de maneira estereotipada indivíduos pertencentes a determinados grupos. Esse autor indica que, ao longo do século XX, houve sucessivas teorias que o estudaram: 1) a teoria da frustração ou do"bode expiatório", que considera o preconceito originado de frustrações sociais, isto é, o indivíduo busca um alvo social que seria, imaginariamente, responsável por seus fracassos; 2) a teoria que considera o preconceito fruto de distúrbios psíquicos - esta concepção, com base na psicanálise, considera que a estrutura da personalidade predisporia o indivíduo a ser preconceituoso e, segundo Duckitt, o estudo sobre a personalidade autoritária de Adorno, Frenkel-Brunswik, Levinson e Sanford (1950) representa esta teoria; 3) a teoria que considera o preconceito uma falha na socialização, isto é, o indivíduo incorporaria princípios e valores sociais em sua formação que o predisporiam ao preconceito; 4) a teoria que considera o preconceito fruto dos conflitos entre as classes sociais - para eliminar o preconceito, seria necessária a mudança da sociedade; e 5) teorias que consideram o preconceito um problema cognitivo e examinam especificamente os estereótipos. O autor argumenta que, apesar de serem teorias que surgem de uma crítica à teoria existente anteriormente, não deixam de ser complementares àquela. Crochík (2006) defende que o estudo sobre a personalidade autoritária de Adorno et al. (1950) contempla todas elas.

Adorno et al. (1950) pesquisaram, entre outras questões, a relação entre ideologia e preconceito. Seus dados empíricos mostraram uma correlação positiva entre a posição político-econômica, avaliada pela escala Conservadorismo Político-Econômico (escala CPE), e a que avalia indiretamente o preconceito (escala F), de magnitude intermediária $(r=0,52)$, o que indica que, se há relação entre essas duas variáveis, elas não são redutíveis uma à outra. 
A ideologia é delimitada por eles como uma maneira de pensar sobre o homem e a sociedade, expressa em opiniões, atitudes e valores. As ideologias são independentes de qualquer indivíduo isolado, posto que são produtos quer de processos históricos, quer de acontecimentos sociais do momento. A ideologia se apresenta em diferentes áreas da vida social: política, economia, religião. Os autores não deixam de dizer que há ideologias mais ou menos racionais, e que a adesão a uma ou a outra depende de necessidades psíquicas individuais; entre elas, a necessidade de se defender do que gera estranheza pela diferença, o que caracteriza os alvos do preconceito; essa estranheza está relacionada à ansiedade e ao medo frente a esses alvos (Horkheimer \& Adorno, 1985). Assim, um indivíduo que não desenvolveu adequadamente o ego, tal como é definido pela psicanálise, tenderá a aderir a ideologias irracionais, como a do fascismo, enquanto aqueles que desenvolveram adequadamente uma distinção entre os seus desejos e a realidade defenderiam uma ideologia democrática. Os autores insistem que o fenômeno estudado tem determinação social, o que impede de considerar a pesquisa sobre a personalidade autoritária um estudo redutível à preocupação com a personalidade, como sugere Brown (1995). No entanto, uma vez que a compreensão dos aspectos individuais associados ao preconceito ainda era insuficiente, julgaram importante enfatizar a importância da personalidade na constituição desse fenômeno.

Tendo em vista a discussão acima, o preconceito, neste estudo, foi considerado uma expressão de atitudes hostis contra minorias e produto das relações entre as necessidades psíquicas e a ideologia.

O estudo de Adorno et al. (1950) foi realizado nos Estados Unidos na década de 1940, e como as ideologias e a estruturação da personalidade modificam-se historicamente (Horkheimer \& Adorno, 1973), julgou-se que contemporaneamente há outra forma de ideologia e outra forma de personalidade existentes. A ideologia econômica e política teria sido substituída pela ideologia da racionalidade tecnológica, e a personalidade autoritária teria sido substituída pela narcisista. Na pesquisa sobre a personalidade autoritária, em um dos capítulos assinados por Adorno (Tipos e Síndromes), o tipo manipulador apresenta características narcisistas e, em um texto posterior, Adorno (1991) apresenta o narcisismo (ou abandono da consciência) como propício aos tempos atuais. Lasch (1983) retoma o estudo dos frankfurtianos para evidenciar a cultura do narcisismo. Quanto à ideologia da racionalidade tecnológica, Marcuse $(1982,1999)$ e Habermas (1983) a delimitam: trata-se menos de uma organização de opiniões e atitudes do que de uma forma sistemática de pensar. Por meio dela, diversos fenômenos (política, economia, saúde, educação, sexualidade) seriam compreendidos de forma sistemática pelo emprego das categorias utilizadas na técnica e na ciência; essas categorias teriam base na razão instrumental, tal como definida por Horkheimer (1976) e, segundo Marcuse (1982) e Habermas, no pensamento formal. Os conflitos e as contradições reais seriam considerados problemas técnicos ou passíveis de serem resolvidos pela técnica.

Crochík (2000) construiu a Escala da Ideologia da Racionalidade Tecnológica (escala I) e, em conjunto com Severiano (2001), a Escala de Características Narcisistas de Personalidade (escala N), e as aplicou, em conjunto com a Escala F, a estudantes universitários. Encontrou correlações significativas, ao nível de 0,01, entre os escores das três escalas: a correlação entre a escala da ideologia da racionalidade tecnológica e a escala de características narcisistas de personalidade foi 0,47; entre a da ideologia e a escala $F$ foi igual a 0,62, e a existente entre a escala $\mathrm{N}$ e a escala $\mathrm{F}$ foi 0,54. Por esses resultados é possível se dizer que a ideologia da racionalidade tecnológica é mais associada à personalidade autoritária, avaliada pela escala F, do que ao narcisismo e, assim, se há a existência desta forma de pensar, o autoritarismo ainda explica mais a personalidade propícia a uma sociedade hierárquica do que o narcisismo, ainda que este não possa ser desconsiderado.

Em outro estudo (Crochík, Ferrari, Hryniewicz, Barros \& Nascimento, 2006), com alunos de cursos de licenciatura, a escala da ideologia da racionalidade tecnológica foi aplicada em conjunto com a escala F e com outra construída por Crochík e Casco (ver Crochík, 2005), chamada Manifestação de Preconceitos (ou escala P). Verificou-se uma correlação significativa entre essas três escalas: F e ligual a 0,71, Fe P igual a 0,56 e l e P igual a 0,38. Esse tipo de ideologia, portanto, está associado também ao preconceito. Nessa mesma pesquisa, foi aplicada uma outra escala, denominada Atitudes Frente à Educação Inclusiva (ou escala E), construída por Crochík 
et al. (2006); essa escala obteve correlações significativas com as demais: a correlação com a escala I foi igual a 0,22; com a escala F, 0,25, e com a escala P, 0,35. Ou seja, em futuros professores, verificou-se que o preconceito, a ideologia da racionalidade tecnológica e o autoritarismo associam-se à atitude contrária à educação inclusiva. A relação com o preconceito explica-se pelo fato de a educação inclusiva favorecer minorias, vítimas de discriminação, que agora devem frequentar a escola regular; quanto à relação da posição contrária à educação inclusiva com a ideologia da racionalidade tecnológica, pode-se supor que isto ocorre porque os adeptos dessa ideologia tendem a separar e classificar os homens, assim como fazem com as coisas, e por defenderem um sistema de educação homogêneo - algo a que a educação inclusiva não se propõe (Ainscow, 1997; Mantoan, 2003; Mittler, 2003); já a correlação com a escala F pode ser explicada pelo desprezo ao mais frágil e pela defesa da estrutura social hierárquica feita pelos sujeitos que aderem à ideologia fascista (Adorno et al., 1950).

A ênfase na racionalidade técnica é criticada por Rodriguez (1992) em sua defesa da educação inclusiva, o que fortalece os resultados de pesquisa acima enunciados. Segundo ele, a formação do professor deveria proporcionar: "unas competencias profesionales que el profesor hoy no tiene. El modelo de racionalidad técnica ha de darpaso a esa figura del profesor como ese profesional reflexivo y con autonomía" (p.10).

B.G. Cook, Tankersley, L. Cook e Landrun (2000), ao estudarem a atitude dos professores de classes inclusivas, também demonstraram haver relação entre as atitudes dos professores e o preconceito. Evidenciaram que os alunos com dificuldades de aprendizagem, em geral, suscitam preocupação e rejeição por parte dos professores.

No que tange às relações sociais entre os alunos e os professores, pesquisas com crianças com e sem deficiência apontaram que elas querem tratamento igual dos professores e da escola. Klingner e Vaughn (1999) analisaram vinte pesquisas que estudaram as atitudes de alunos de classes regulares que incluíam estudantes com deficiências frente às posturas dos professores na aula, e concluíram que as crianças, com ou sem dificuldades, querem que todos sejam submetidos às mesmas atividades individuais e de grupo, e aos mesmos livros. Elas não se importam que os professores adaptem métodos ou despendam mais tempo para explicar algo para os alunos que não conseguiram entender determinado assunto, e gostam de auxiliar os colegas que têm mais dificuldades.

Entre os diversos participantes cotidianos da educação, vários são os que interessariam a esta pesquisa, entre eles, o pedagogo, que tem funções importantes em diversas esferas, da cotidiana à formulação de leis, passando pela orientação e supervisão dos professores e demais agentes educacionais da escola. Por isso, nesta pesquisa, foram estudados futuros pedagogos quanto à sua posição em relação à educação inclusiva.

Assim, considerando o que foi exposto nesta introdução, os objetivos da pesquisa relatada neste artigo foram: 1) verificar atitudes de alunos de um curso de pedagogia em relação à educação inclusiva; 2) examinar as possíveis relações das atitudes acerca da educação inclusiva com a ideologia da racionalidade tecnológica, com a manifestação de preconceito e com a escala F.

\section{Participantes}

Fizeram parte deste estudo 188 estudantes de um curso de pedagogia da cidade de São Paulo; 145 cursavam o primeiro ano, 26 cursavam o segundo ano e 17 o terceiro ano. Foram comparados os resultados dos alunos nas diversas escalas, que serão descritas a seguir, considerando o ano letivo em que se encontravam, pela análise de variância. Com 2 e 185 graus de liberdade, verificou-se que essas escalas não diferenciaram significativamente esses grupos, ao nível de 0,01. Os valores encontrados foram: Escala de Atitudes Frente à Educação Inclusiva: $F=1,74$; Escala de Manifestação de Preconceitos: $F=1,08$; Escala da Ideologia da Racionalidade Tecnológica: $F=2,16$; e Escala do Fascismo: $F=1,40$. Com esses resultados, consideraram-se os três grupos de alunos como pertencentes a uma mesma população, e os diversos cálculos foram feitos considerando-se os 188 sujeitos como uma única amostra.

\section{Instrumentos}

a) Questionário de dados gerais dos sujeitos: constava de sete questões referentes à data de nascimento, curso, religião, cor da pele, se tinha deficiência física e parentes próximos com deficiência mental; 
b) Escalas: Foram aplicadas três escalas do tipo Likert, construídas em pesquisas anteriores (Crochík, 2000, 2005; Crochík et al., 2006): "Atitudes Frente à Educação Inclusiva" (escala E), "Adesão à Ideologia da Racionalidade Tecnológica" (escala l) e"Manifestação de Preconceitos" (escala P), além da "Escala do Fascismo" (escala F), desenvolvida por Adorno et al. e traduzida porCrochík (1999).

As escalas utilizadas contêm seis alternativas de resposta, variando entre "discordo plenamente" (um ponto) e "concordo plenamente" (sete pontos), sem a existência de ponto neutro (que corresponderia a quatro pontos). No caso desta pesquisa, quanto maior a concordância com os itens, mais é contrária a atitude frente à educação inclusiva, maior a manifestação do preconceito, maior a adesão à ideologia da racionalidade tecnológica e maior a adesão implícita ao fascismo. Não obstante, as escalas E, I e P tiveram alguns itens invertidos, cujas respostas foram convertidas no sentido acima indicado para os cálculos dos escores dos sujeitos. O número de itens de cada escala utilizada para este estudo foi determinado pela obtenção do Alfa de Cronbach. Os itens foram retirados até se obter para o conjunto de dados o maior valor possível.

A Escala da Ideologia da Racionalidade Tecnológica foi elaborada por Crochík (1999) com base em textos de Horkheimer (1976), Marcuse (1982), Habermas (1983), Horkheimer e Adorno (1985). Inicialmente foram elaborados 42 itens, que foram reduzidos a $20 \mathrm{em}$ aplicações posteriores, para diminuir o tempo de aplicação. Tal como desenvolvido na introdução, essa ideologia diz respeito a uma forma de pensamento que utiliza a sistematização, a classificação, a normalização e o pragmatismo para analisar qualquer objeto em detrimento de suas particularidades - devidas a condições históricas e sociais. Dessa maneira, a política, a economia, a saúde, a educação e a sexualidade são examinadas pela mesma forma de pensar que considera principalmente a adaptação às condições vigentes. Para esta forma de pensar, cujo conteúdo é a forma, os diversos objetos não podem ser diferentes da forma pela qual são percebidos e refletidos pela razão instrumental. Em estudos anteriores (Crochík, 2000, 2005; Crochík et al., 2006), foram obtidos os seguintes coeficientes do Alfa de Cronbach: 0,76, 0,72, 0,82, e para os dados desta pesquisa esse coeficiente foi de 0,60, com a escala reduzida a oito itens.
A Escala de Manifestação de Preconceitos foi criada por Crochík e Casco e apresentada por Crochík (2005): é composta de 24 itens do tipo Likert, seis deles para cada uma das seguintes minorias: negro, judeu, indivíduo com deficiência física e indivíduo com deficiência mental. Essa escala foi construída em formato semelhante ao da escala F. Foi elaborada a partir de outras escalas, tais como a Escala de Antissemitismo e a Escala de Etnocentrismo, elaboradas por Adorno et al. (1950), e da literatura específica sobre o preconceito contra os quatro alvos analisados. Os alfas de Cronbach obtidos para a escala $P$ nas pesquisas anteriores citadas acima variaram de 0,70 a 0,90. Para os dados desta pesquisa, obteve-se um índice de 0,67 para 13 itens utilizados.

A Escala de Atitudes Frente à Educação Inclusiva (escala E) foi proposta com 11 itens (Crochík et al., 2006). Seus itens foram formulados tomando como base os textos dos defensores desse tipo de educação (Ainscow, 1997; Mittler, 2003; Mantoan, 2003). O Alfa de Cronbach encontrado na pesquisa anterior foi 0,68 e, com os dados desta pesquisa, com cinco itens, foi 0,67. Essa escala envolveu itens referentes unicamente às crianças com deficiência, especialmente a deficiência mental, que, segundo Mittler (2003) e S. Stainback e W. Stainback, (1999), são o tipo de aluno que provavelmente exige maior modificação na didática dos professores e oferece maior desafio para aprender o que é ensinado.

A escala F utilizada foi a versão final de Adorno et al. (1950), que apresentava 29 itens. Foi excluído um item por dizer respeito basicamente à época em que foi construída, e outros dois para aumentar o valor do Alfa de Cronbach. Em pesquisas anteriores (Crochík, 2005; Crochík et al., 2006), os Alfas de Cronbach obtidos foram 0,83 e 0,84 , e o obtido com os dados desta pesquisa foi 0,77, com 26 itens.

Os itens das escalas que restaram após os cálculos dos coeficientes Alfa de Cronbach encontram-se em anexo. Cabe ressaltar que os resultados apresentados neste artigo foram feitos considerando-se unicamente esses itens.

\section{Procedimentos}

Para a aplicação dos instrumentos, foi obtido o consentimento dos professores e marcada uma data, sem que os alunos fossem avisados. Os instrumentos 
foram aplicados por dois pesquisadores que, após a distribuição do material, liam as instruções e respondiam as dúvidas que porventura existissem. O tempo médio de aplicação foi de 35 minutos.

A ordem de apresentação dos instrumentos aos sujeitos foi: 1) questionário de dados gerais; 2) instruções de respostas às escalas; 3 ) escalas. Os itens das escalas foram apresentados em conjunto, em ordem aleatória, independentemente das escalas às quais pertenciam. Para obter essa ordem de apresentação dos itens, utilizou-se um sorteio por meio de tábua de números equiprováveis.

Para controle das respostas dos sujeitos, um dos itens foi repetido; os sujeitos que apresentaram diferenças superiores a um ponto nas duas apresentações dessa questão, ou que escolheram a alternativa "concordo" em uma delas e "discordo" em outra, foram retirados da amostra. Não foram considerados, no cômputo dos escores das escalas, os questionários dos sujeitos que pertenciam às minorias referidas na escala P (negros, judeus, indivíduos com deficiência física e indivíduos com deficiência mental), posto que se considerou que eles poderiam estar respondendo de forma distinta dos demais sujeitos, por serem presumidamente alvos do preconceito.

Os dados foram digitados sempre em duplas de pesquisadores, que, após a digitação, conferiam os dados.

\section{Resultados}

Pode-se observar (Tabela 1), que a média da escala E foi próxima à alternativa "leve discordância" (três pontos), e que as demais médias situam-se próximas ao ponto médio (quatro pontos). Deve-se lembrar que, quanto maior a pontuação, mais os sujeitos são contrários à educação inclusiva, mais são preconceituosos, mais são adeptos da ideologia da racionalidade tecnológica e evidenciam maior tendência implícita ao fascismo.

Todas as correlações apresentadas na Tabela 2 são significativas ao nível de 0,01 e, assim, pode-se dizer que há associação significante entre todas as variáveis estudadas nesta pesquisa. Nota-se, contudo, que as escalas P e F estão mais associadas à escala E do que a
Tabela 1. Média e desvio-padrão obtidos por meio das escalas aplicadas a alunos de cursos de Pedagogia. São Paulo (SP), 2006

\begin{tabular}{lcc}
\hline Escalas & Média & Desvio-padrão \\
\hline E & 3,08 & 1,30 \\
$P$ & 3,64 & 0,93 \\
I & 4,35 & 1,12 \\
F & 4,16 & 0,84 \\
\hline
\end{tabular}

Tabela 2. Correlações de Pearson entre as escalas aplicadas a alunos de cursos de Pedagogia. São Paulo (SP), 2006.

\begin{tabular}{lcccc}
\hline Escalas & $E$ & $P$ & I & $F$ \\
\hline$E$ & & 0,45 & 0,28 & 0,42 \\
$P$ & 0,45 & & 0,40 & 0,50 \\
I & 0,28 & 0,40 & & 0,64 \\
$F$ & 0,42 & 0,50 & 0,64 & \\
\hline
\end{tabular}

Todas as correlações apresentadas na são significativas ao nível de 0,01.

escala I, o que parece sugerir que o preconceito e a adesão implícita ao ideário fascista têm maior poder preditivo sobre a atitude em relação à educação inclusiva do que a adesão à ideologia da racionalidade tecnológica. A regressão linear realizada confirma esta hipótese. Ao se considerar a escala E como variável dependente e as demais como variáveis independentes, obteve-se um $R^{2}=0,25$, significante para a Escala $\mathrm{F}(t=3,12$; $p=0,002)$ e para a Escala $\mathrm{P}(t=4,28 ; p=0.000)$, mas não para a escala I $(t=-0,24 ; p=0,849)$. Os coeficientes beta obtidos nas escalas foram: Escala $F=0,28$, Escala $P=0,32$ e Escala $I=-0,02$. Essa análise de regressão indica que o preconceito e a tendência implícita ao fascismo têm poder preditivo em relação à atitude frente à educação inclusiva, o que não ocorre com a ideologia da racionalidade tecnológica.

\section{Discussão}

No que se refere ao primeiro objetivo desta pesquisa, verificou-se que os estudantes de pedagogia da amostra tenderam, em média, a ser pouco mais favoráveis do que desfavoráveis à educação inclusiva, referida especialmente aos alunos com deficiência; destaca-se, contudo, que não são plenamente favoráveis a esse tipo de educação. Como esses estudantes provavelmente serão professores, a sua posição frente a esse tipo de educação é fundamental, pois, segundo Gracia 
(2000), os professores podem ser considerados os agentes mais importantes no processo educativo. Por meio do exercício de sua autoridade pedagógica, o professor pode proporcionar o desenvolvimento de relações cooperativas e solidárias, facilitando a inclusão de crianças com deficiência, ou agir em sentido contrário a esta inclusão. Pela tendência a discordar dos itens da escala Atitudes Frente à Educação Inclusiva, pode-se pensar que os sujeitos desta pesquisa, ao menos, não se oporão a que alunos com deficiência frequentem classes de aula regulares. Apesar disso, como os sujeitos desta pesquisa tenderam a discordar pouco das afirmações, há motivos para que as discussões na área continuem, para que os possíveis futuros professores e educadores possam lutar mais intensamente por esse tipo de educação.

Quanto ao segundo objetivo desta pesquisa, verificou-se que há relação entre as variáveis. Portanto, quanto mais o sujeito é contrário à educação inclusiva, maior é a sua manifestação de preconceitos, mais a sua forma de pensar tende a ser sistemática e técnica, e maior é sua tendência implícita ao fascismo. As correlações obtidas entre as variáveis, no entanto, não foram de igual magnitude. Foram obtidas correlações mais elevadas das escalas P e F com a escala E, em comparação com a correlação entre a escala I e a escala $E$. Portanto, o preconceito e a adesão ao ideário fascista têm maior poder de determinação, se comparados à ideologia da racionalidade tecnológica, sobre a atitude em relação à educação inclusiva. Se a configuração social é importante para a constituição dos indivíduos, a ideologia fascista constitui uma das expressões culturais que parece estar relacionada à formação de indivíduos preconceituosos. A correlação obtida neste estudo entre as escalas P e F reforça esta hipótese. Se o fascista divide os homens em fracos e fortes e almeja a sua separação, com a dominação dos últimos sobre os primeiros, não é de se estranhar que quem pense desta forma seja contrário à educação inclusiva. De forma similar, pode-se pensar que como o preconceituoso tem dificuldades de se relacionar com os que são diferentes, imaginando que sejam uma ameaça, é compreensível que queira que os indivíduos com deficiência estudem em lugar segregado.

Se aquele que tende ao fascismo e o preconceituoso precisam manter a realidade tal como está, se são avessos às mudanças e desprezam a fragilidade (Adorno et al., 1950), a educação inclusiva contém alterações importantes no ensino e propõe incluir minorias consideradas frágeis, tais como os indivíduos com deficiência, o que pode explicar as relações encontradas. Esse resultado corrobora a preocupação de Rodriguez (1992) e Mantoan (2003) acerca das atitudes dos professores frente às novas exigências da atuação profissional, que rompem com esquemas convencionais de organização da aula, pois esses professores podem impedir a inclusão das crianças com ritmo mais lento na aprendizagem escolar. Como as correlações, ainda que significativas, não são de alta magnitude, pode-se supor que alguns sujeitos que concordam com premissas fascistas e que são preconceituosos defendam igualmente a educação inclusiva, talvez por considerarem que a presença dos indivíduos deficientes na escola reforce sua pretensa superioridade, mas essa é uma hipótese que precisaria ser examinada por outros estudos.

No que se refere à menor magnitude obtida pela correlação entre a escala I e a escala E, pode-se concluir que o valor preditivo da ideologia da racionalidade tecnológica sobre as atitudes com relação à educação inclusiva é quase nulo. No entanto, como essa ideologia se contrapõe à ideia de uma educação humanista, não deixa de ser preocupante tanto a adesão a ela (indicada pela média obtida) como a correlação verificada entre essa variável e a escala de atitudes frente à educação inclusiva. Como discutido anteriormente, uma das características dos indivíduos que aderem à ideologia da racionalidade tecnológica diz respeito à dificuldade que apresentam em refletir sobre os efeitos políticos de suas ações, assim como em aprender com as experiências (posto que só conseguem perceber o mundo por meio de categoria técnicas, o que dificulta que tenham experiências com o que é particular e, assim, distinto) e compreender que o mundo não é estático: modifica-se historicamente. Tais características tendem a se coadunar com a cultura que valoriza as relações de poder entre os homens, sustentadas na suposta neutralidade científica e tecnológica. Essa disposição pode dificultar a implantação de novas concepções de conhecimento que pautem as proposições para a educação inclusiva, pois, como afirma Rodriguez (1992), tais concepções estariam estruturadas na articulação entre as investigações científicas sobre o processo ensino/aprendizagem, a prática e a experiência acumuladas pelos professores, tendo em vista redimensionar as relações entre a técnica, a reflexão e a criatividade. Deve-se 
considerar também que se a correlação, apesar de significativa, foi de baixa magnitude, isso pode implicar que parcela importante dos sujeitos que adere a esta ideologia é favorável à educação inclusiva. Isso pode ser entendido pela suposição de que a escola pode aprimorar os seus instrumentos técnicos, de forma a retirar paulatinamente as diferenças existentes. Certamente, a crença no progresso linear e infinito, própria a esse tipo de ideologia, sustentaria tal explicação, que deveria ser confirmada empiricamente. Caberia entrevistar esses sujeitos para aprofundar o entendimento de suas respostas às questões da Escala de Atitudes Frente à Educação Inclusiva.

Tendo em vista que o preconceito e as ideologias examinadas, sobretudo a fascista, podem ser obstáculos à implantação e implementação da educação inclusiva, conforme mostram os dados desta pesquisa, caberia combater esses fenômenos de modo a fortalecer um tipo de educação que seja inerente à democracia, por permitir que as diferenças sejam cada vez mais bem expressadas.

\section{Referências}

Adorno, T. W. (1991). De la relación entre sociología y psicología. In T.W. Adorno. Actualidad de la filosofia (pp.135-204). Barcelona: Ediciones Paidós Ibérica. (Originalmente publicado en 1955).

Adorno, T. W., Frenkel-Brunswik, E., Levinson, D. J. \& Sanford, R. N. (1950). The authoritarian personality. New York: Harper and Row.

Ainscow, M. (1997). Educação para todos: torná-la uma realidade. In M. Ainscow, G. Porter \& M. Wang. Caminhos para as escolas inclusivas. Lisboa: Instituto de Inovação Educacional.

Brasil. Ministério da Educação e Cultura. (1996). Lei No 9.394 de 20 de dezembro de 1996. Lei de Diretrizes e Bases da Educação Nacional - LDB. Brasília: MEC.

Brasil. Ministério da Educação e Cultura. (2005). Secretaria de Educação Especial (SEESP/MEC) (2005). Dados do censo escolar de 2005. Brasília: MEC.

Brown, R. (1995). Prejudice: its' social psychology. Oxford: Blackwell Publishers.

Cook, B. G., Tankersley, M., Cook, L., \& Landrun, T. J. (2000). Teacher's attitudes toward their included students with disabilities. Exceptional Children, 67 (1), 115-135.

Crochík, J. L. (1999). A Ideologia da racionalidade tecnológica e a personalidade narcisista. Tese de doutorado não-publicada, Universidade de São Paulo.

Crochík, J. L. (2000). Tecnologia e individualismo: um estudo de uma das relações contemporâneas entre ideologia e personalidade. Análise Psicológica, 18 (4), 529-543.
Crochík, J. L. (2005). Preconceito: relações com a ideologia e com a personalidade. Estudos de Psicologia (Campinas), 22(3), 307-319.

Crochík, J. L. (2006). Preconceito, indivíduo e cultura (3a. ed.). São Paulo: Casa do Psicólogo.

Crochík, J. L., Ferrari, M. D., Hryniewicz, R. R., Barros, O. N., \& Nascimento, R. B. (2006). Preconceito e atitudes em relação à educação inclusiva. Psicologia Argumento, 24 (46), 55-70.

Duckitt, J. (1992). Psychology and prejudice: a historical analysis and integrative framework. American Psychologist, 47 (10), 1182-1193.

Gracia, V. S. (2000). La Educación integradora en Europa. Valencia: Artes Gráficas Soler.

Guiford J. P., \& Fruchter, B. (1973). Fundamental statistics in psycology and education (5th ed.). New York: McGraw-Hill.

Habermas, J. (1983). Técnica e ciência enquanto ideologia. In W. Benjamin, M. Horkheimer, T. W. Adorno \& J. Habermas. Textos escolhidos (pp.313-343). São Paulo: Abril Cultural.

Horkheimer, M. (1976). A eclipse da razão. Rio de Janeiro: Editorial Labor.

Horkheimer, M., \& Adorno, T. W. (1973). Temas básicos da sociologia. São Paulo: Cultrix.

Horkheimer, M., \& Adorno, T. W. (1985). Dialética do esclarecimento (2a ed.) Rio de Janeiro: Jorge Zahar Editor.

Klingner, J. K., \& Vaughn, S. (1999). Students' perceptions of instruction in inclusion classrooms: implications for students with learning disabilities. Exceptional Children, 66 (1), 23-37.

Lasch, C. (1983). A cultura do narcisismo: a vida americana numa era de esperancas em declínio. Rio de Janeiro: Imago.

Mantoan, M. T. E. (2003). Inclusão escolar: o que é? Por quê? Como fazer? São Paulo: Moderna.

Marcuse, H. (1982). Aideologia da sociedade industrial (6a ed.). Rio de Janeiro: Zahar.

Marcuse, H. (1999). Industrialização e capitalismo na obra de Max Weber. In H. Marcuse. Cultura e sociedade (Vol.2, pp.113-136). Rio de Janeiro: Paz e Terra.

Mittler, P. (2003). Educação inclusiva: contextos sociais. Porto Alegre: Artmed.

Rodríguez, J. S. (1992). La integración: un cambio en las concepciones del profesor. Revista de Educación Especial, $12(3), 9-15$.

Severino, M. F.V. (2001). Narcisimo e publicidade: uma análise psicossocial dos ideais do consumo na contemporaneidade (Vol 1). São Paulo: Annablume.

Siegel, S., \& Castellan, N. J. (2006). Estatística não-paramétrica para ciências do comportamento (2a ed.) Porto Alegre: Artmed.

Stainback, S., \& Stainback, W. (1999). Inclusão: um guia para educadores. Porto Alegre: Artes Médicas Sul.

Recebido em: 14/12/2007

Versão final reapresentada em: 22/8/2008

Aprovado em: 16/10/2008 


\section{ANEXO}

\section{ITENS UTILIZADOS NA APLICAÇÃO DA ESCALA}

P-01- Como negros e brancos têm preferências específicas quanto a tipos de música e de dança, não é de se estranhar que existam casas noturnas frequentadas quase exclusivamente por negros e outras por brancos.

1-03- O socialismo é um sistema que contém belos ideais teóricos, porém não aplicáveis na prática.

F-06- Algum dia se provará talvez que a astrologia pode explicar muitas coisas.

1-07- Se a pena de morte diminuir a criminalidade, ela deve ser aprovada.

F-08- A obediência e o respeito à autoridade são as principais virtudes que devemos ensinar a nossas crianças.

F-10- Um indivíduo de más maneiras, maus costumes e má educação dificilmente pode fazer amizade com pessoas decentes.

P-11- O portador de deficiência física, na maioria das vezes, lembra-me a imperfeição humana.

F-14- O que este país necessita, primordialmente, antes de leis ou planos políticos, é de alguns líderes valentes, incansáveis e devotos em quem o povo possa depositar a sua fé.

F-18- Não se concebe nada mais baixo do que uma pessoa que não sente profundo amor, gratidão e respeito por seus pais.

F-23- Os homens podem ser divididos em duas classes definidas: os fracos e os fortes.

P-25- O avanço da medicina com os seus métodos de detectar imperfeições nos fetos é importante, pois impede o nascimento de pessoas com deficiência mental.

P-26- Os negros, em geral, têm uma inclinação para os esportes e para a música.

F-29- Só por meio do sofrimento se aprendem as coisas verdadeiramente importantes.

F-31- A ciência tem o seu lugar, mas há muitas coisas importantes que a mente humana jamais poderá compreender.

P-32- Em geral, os portadores de deficiência física tentam compensar a sua deficiência sobressaindo-se nas atividades intelectuais.

F-34- Às vezes, os jovens têm ideias rebeldes que, com os anos, deverão superar para assentar os seus pensamentos.

F-37- Se falássemos menos e trabalhássemos mais, todos estaríamos melhor.

F-39- Todos devemos ter fé absoluta em um poder sobrenatural, cujas decisões devemos acatar.

P-40- As escolas judaicas deveriam dar menos ênfase ao judaísmo e mais atenção a valores como a solidariedade.

F-41- Os homossexuais são quase criminosos e deveriam receber um castigo severo.

F-43- Nenhuma pessoa decente, normal e em seu são juízo pensaria em ofender um amigo ou parente próximo.

P-44- Uma das piores fatalidades que pode acontecer a uma pessoa é ser portador de deficiência mental.

1-45- O lazer agradável acontece depois do dever cumprido.

F-46- Hoje em dia, as pessoas se intrometem cada vez mais em assuntos que deveriam ser estritamente pessoais e privados.

P-47- Frequentemente, os negros, por sua forma de ser despretensiosa, têm maior dificuldade em conseguir cargos de chefia.

E-48- Os alunos portadores de deficiência, no ensino integrado/inclusivo, sentem-se desmotivados em sala de aula por não conseguirem acompanhar o ritmo de outros alunos.

1-49- Com os recursos científicos e tecnológicos de hoje somos mais felizes do que antigamente.

1-50- Os pais devem mostrar carinho pelos filhos, mesmo que não seja espontâneo.

P-51- Geralmente, as pessoas com deficiência mental não são atraentes.

F-53- Os crimes sexuais tais como o estupro ou ataques a crianças merecem mais que prisão; quem comete esses crimes deveria ser açoitado publicamente ou receber um castigo pior.

F-55- Deve-se castigar sempre todo insulto à nossa honra.

P-56- Os judeus, em geral, preferem frequentar as suas próprias organizações - clubes, escolas etc.

F-57- A maioria de nossos problemas sociais estaria resolvida se pudéssemos nos livrar das pessoas imorais, dos marginais e dos débeis mentais.

1-59- As telenovelas são boas quando apresentam personagens que são facilmente identificáveis no cotidiano.

F-60- Quando alguém tem problemas ou preocupações, é melhor não pensar neles e se ocupar de coisas mais agradáveis.

E-61- O ritmo mais rápido dos alunos sem deficiência prejudica o aprendizado dos alunos portadores de deficiência, quando estudam conjuntamente.

1-62- As prostitutas deveriam ter atendimento psicológico e reeducação para terem melhor encaminhamento na vida.

\section{$\boldsymbol{\nabla} \nabla \boldsymbol{\nabla} \nabla$}

3 Neste anexo, a letra P refere-se à escala de manifestação de preconceitos; a letra I, à escala da Ideologia da Racionalidade Tecnológica; a letra E, à Escala de Atitudes Frente à Educação Inclusiva; e a letra F, à escala F. 
F-64- A vida sexual desenfreada dos antigos gregos e romanos era um jogo inocente em comparação com o que sucede neste país, mesmo nos lugares menos imagináveis.

1-65- Em alguns casos, seria importante que o homossexual tivesse um acompanhamento psicológico para poder rever a sua escolha sexual.

F-66- A maioria das pessoas não imagina até que ponto a vida está dirigida por conspirações forjadas em lugares secretos.

E-67- Os alunos portadores de deficiência devem estudar em ambientes separados dos outros alunos.

F-68- Hoje em dia, em que tantas classes diferentes de pessoas andam e se misturam por todos os lados, as pessoas devem se proteger, com especial cuidado, contra o contágio de infeções e enfermidades.

F-70- Tal como é a natureza humana, sempre haverá guerras e conflitos.

P-72*-A presença de uma pessoa com deficiência mental não me causa mal-estar.

E-73*-Sou favorável à inclusão de alunos portadores de deficiência nas salas de aula regulares.

F-74- Algumas pessoas nascem com necessidade de saltar de lugares altos.

F-75- O que este país necessita, primordialmente, antes de leis ou planos políticos, é de alguns líderes valentes, incansáveis, e devotos em quem o povo possa depositar a sua fé.

E-76- No ensino integrado/inclusivo, os alunos sem deficiência apresentam comportamentos inadequados ao se identificarem com alunos portadores de deficiência.

F-77- Nenhuma fragilidade ou dificuldade pode nos deter, quando temos suficiente força de vontade.

1-80- O avanço da medicina com os seus métodos de detectar imperfeições nos fetos é importante, pois impede o nascimento de pessoas com defeitos físicos.

F-81- Do que mais necessita a nossa juventude é de uma disciplina estrita, firme determinação e vontade de trabalhar e lutar pela família e pela pátria.

F-84- As guerras e os conflitos sociais podem acabar algum dia por obra de um terremoto ou de uma inundação que destrua o mundo inteiro. 